\title{
إعلان سان فرانسيسكو حول تقييم البحوث
}

\section{San Francisco Declaration on Research Assessment ${ }^{*}$}

\section{Khaled Moustafa ${ }^{\dagger}$ Kصطف مصفى}

هناك حاجة ملحة لتحسين طرق تقييم مخرجات البحث العلمي من قبل وكالات التمويل والمؤسسات الأكاديمية وأطراف أخرى. لمناقثة هذه المسألة، اجتمعت مجموعة من محرري وناشري المجلات العلمية خلال اللقاء السنوي للجمعية الأمريكية لعلم الأحياء الخلوي (ASCB)، في سان فرانسيسكو، كاليفورنيا، 16 كانون الأول 2012، ووضعت حزمة من التوصيات، يثار إلبها باسم "إعلان سان فرانسيكو حول تقييم البحوث". ندعو الأطراف المعنية من جميع التخصصات إلى دعم هذا الإعلان بإضافة أسمائهم إليه. إن مخرجات البحث العلمي كثيرة ومتتوعة، وتشمل: مقالات بحث نتبثق عنها معارف جديدة، أو بيانات أو كواثف كيميائية أو برمجيات حاسوبية؛ وأعمال فكرية إبداعية؛ وعلماء شباب مؤهلين تأهيلاً عالياً، إلخ. وهنالك رغبة وحاجة، لدى وكالات التمويل والعلماء أنفسهم والمؤسسات التي توظفهم، إلى تقييم جودة المخرجات العلمية وتأثثرها. لذلك، من الضروري قياس الناتج العلمي بدقة وتقييمه بحكمة. كثيراً ما يستخدم معامل تأثير المجلات العلمية journal impact factor كمعيار أولي لمقارنة الناتج العلمي للأفراد والمؤسسات. وقد تم بالأصل إنشاء هذا المعامل- والذي تقوم بحسابه الآن شركة "كلاربفيت آناليتكس Clarivate Analytics"- كأداة لمساعدة أمناء المكتبات على تحديد المجلات المرغوب بشرائها أو الاشتراك بها، وليس كمقياس للجودة العلمية. آخذين ذلك في الاعتبار، من الضروري فهم أن استخدام معامل التأثير كأداة لتقييم البحث تشوبه كثير من العيوب التي أُسهِب فيها كثيراً، نذكر منها ما يلي: أ) هناك خلل كبير في توزّع الاقتباسات بين المجلات المختلفة (يُستشهد ببعض المجلات أكثر من غيرها). ب) اعتماد خصائص معامل التأثير على مجال التخصص: فهو حصيلة أنواع متعددة من المقالات، كالمقالات البحثية والمراجعات النقدية إلخ [1، 4]. ج) إمكانية التلاعب بقيمة معامل التأثير من خلال سياسة التحرير [5]. د) البيانات المستخدمة لحساب معامل التأثير غير مُتاحة للعموم وتفتقد إلى الثفافية [4، 6، 7].

\footnotetext{
" ${ }^{*}$ https://sfdora.org/read/ رابط الإعلان:
}

† 
لذلك، نقام أدناه عدداً من التوصيات لتحسين الطريقة التي يتم بها تقييم جودة مخرجات البحوث. وستزداد مستقبلاً أهمية المقالات غير البحثية في تقييم فعالية البحث، ولكن تبقى المقالات المُحكمّة محورية في ثقييم

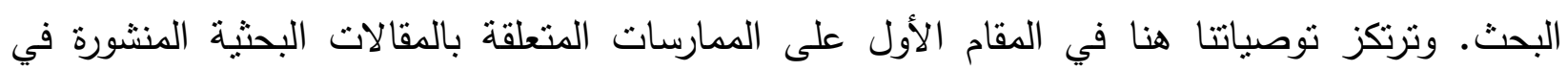
مجلات علمية مُحكمّة، ولكن يمكن، بل ينبغي، توسيعها لتشمل الاعتراف بمنتجات علمية أخرى، مثل لتل

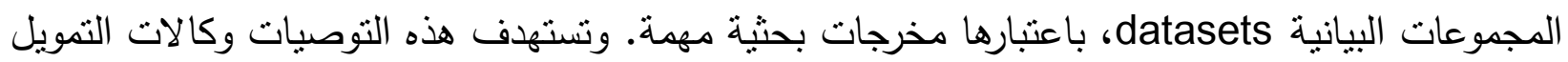
والمؤسسات العلمية والمجلات والمنظمات التي تقدم المقاييس العلمية، والباحثن الأفراد. سينم التطرق إلى عدد من الموضوعات ضمن إطار هذه التوصيات: - ضرورة الابتعاد عن استعمال معايير التقييم المتعلقة بالمجلات، مثل معامل التأثير impact factor، في طلبات التمويل والتوظيف والتزرقية. - ضرورة تقييم البحوث على أساس قيمتها الحقيقية، وليس على أساس المجلة التي تُشر فيها.

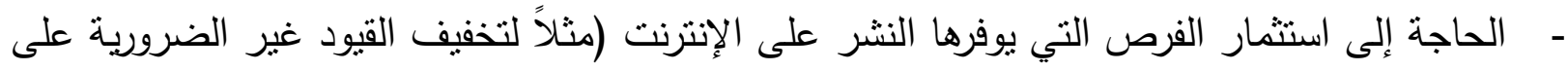
عدد الكلمات والأشكال والمراجع المسوح بها في المقالات، واسنتباط مؤشرات جديدة حول الأهمية والتأثير)

ندرك أن العديد من وكالات التمويل والمؤسسات والناشرين والباحثين يثجعون للتو على تحسين أساليب تقييم البحوث. وقد بدأت تلك الخطوات بإعطاء زخةٍ نحو طرق أكثر تطوراً لتقييم البحوث، ويمكن تبنيها واعتمادها الآن من قبل جميع الدوائر الرئيسية المعنية.

يدعم الموقعون على إعلان سان فرانسيسكو حول تقييم البحوث تبني الممارسات التالية عند تقييم البحوث. توصية عامة

1 إسم استخدام معايير تقييم تعتمد على المجلات، مثل معامل التأثثر impact factor، كمقياس لجودة المقالات أو لتقييم المساهمات العلمية أو للبت في قرارات التوظيف أو الترقية أو التمويل.

لوكالات التمويل

2) بيان المعايير المستخدمة بوضوح في تقييم الإنتاجية العلمية للمتقدمين بطلبات تمويل، والتأكيد خاصة للمبندئين على أن المحتوى العلمي للمقالات هو أكثر أهمية من مقاييس النشر أو هوية المجلة الناشرة. 
3) لأغراض تقييم البحوث، الأخذ بالاعتبار قيمة وتأثير جميع أنواع المخرجات العلمية (بما في ذلك المجموعات البيانية والبرمجيات الحاسوبية) بالإضافة إلى منشورات الأبحاث، واعتماد مجموعة واسعة من معايير التأثير ، بما في ذلك المؤشرات النوعية لنتائج البحوث، كالتأثثير على السياسة والتطبيق.

\section{للمؤسسات}

4) الوضوح في اتخاذ قرارات التوظيف، والتثبيت، والتزقية، والتركيز، خاصة للمبتدئين، على أن المحتوى العلمي للمقالة هو أكثر أهمية من مقاييس النشر أو هوية المجلة النانشرة. 5) لأغراض تقييم البحوث، الأخذ بالحسبان قيمة وتأثير جميع أنواع المخرجات العلمية (بما في ذلته

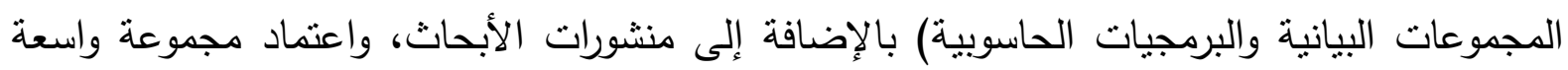
من معايير التأثير ، بما في ذلك المؤشرات النوعية لنتائج البحوث، كالتأثير على السياسة والتطبيق.

6) تقليل التركيز على معامل تأثنير المجلات العلمية كأداة ترويجية، من خلال التوقف عن تعزيز قيمة هذا المعامل، أو تقديمه ضمن سياق مجموعة أخرى من معايير التقييم المختلفة (مثناً، حساب معامل التأثير

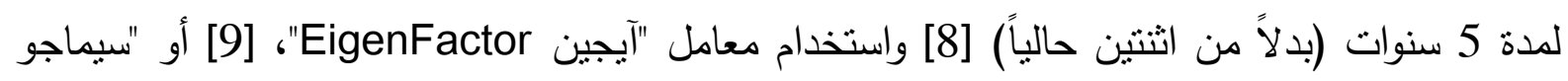

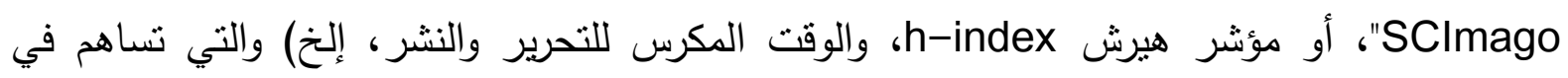
إعطاء نظرة أعمق حول أداء المجلة. 7) إتاحة مجموعة من معايير التقييم المرتكزة على المقالات العلمية بدلاً من الاستتاد إلى مقاييس المجلة الناشرة، وذللك لتتجيع التحول نحو التقييم المستتد إلى المحتوى العلمي للمقالة وليس للمجلة. 8) التشجيع على تحمّل المسؤولية في التأليف، وبيان مساهمة كل مؤلف على حدة. 9) سواء كانت المجلة مفتوحة المدخل open access أو معتمدة على الاشتراك، أزيلوا جميع قيود إعادة استخدام المراجع واجعلوها متاحة ضمن "مجال الإبداع المُشاع للعموم" Creative Commons Public .[10] Domain 10) إزالة أو تخفيف القيود المفروضة على عدد المراجع المسموح بها في المقالات العلمية، والتركيز كلما

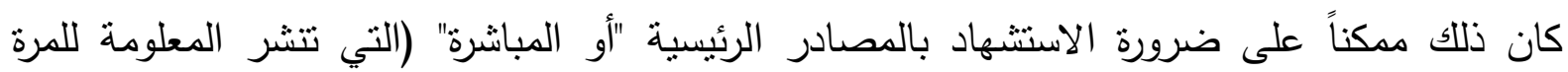

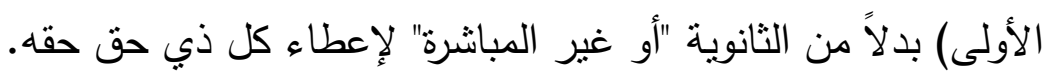


11) اعتماد الانفتاح والثفافية في إظهار البيانات والطرق المستخدمة لحساب جميع المقاييس.

12) تقديم البيانات بموجب ترخيص يسمح بإعادة استخدامها دون قيد، وإتاحة الوصول إليها عن طريق الحاسب (الإنترنت)، حيثما كان ذلك ممكناً.

13) الإشارة بوضوح إلى عدم التسامح مع التلاعب بالمقاييس، وبيان ما يمكن أن يشكل خرقاً لها، وما هي التدابير المتخذة لردع ذلك.

الأخذ بالحسبان التباين في أنواع المقالات العلمية (مراجعات نقدية، مقالات بحث تجريبية إلخ)، والتباين في مجالات التخصص المختلفة عند استخدام تلك المقاييس، أو تجميعها، أو مقارنتها.

15) عند المشاركة في لجان اتخاذ قرارات التموبل، أو التوظيف، أو التبيت، أو الترقية، ركزوا على التقييم على أساس المحتوى العلمي بدلاً من مقاييس النشر .

16) استشهدوا، ما أمكن، بالمصادر الأصلية التي تورد المعلومات للمرة الأولى بدلاً من المصادر الثانوية لإعطاء كل ذي حق حقه.

استخدموا مجموعة من مقاييس ومؤثرات التقييم عند إصدار توصيات داعمة أو بيانات شخصية، كدليل على تأثنر المقالات الفردية المنشورة وغيرها من مخرجات البحث [11]. 18) اطعنوا في أساليب تقييم البحوث المعتمدة على معامل التأثير بشكل غير مناسب، واعملوا على تعزيز وتدريس أفضل الممارسات التي ترتكز على قيمة المخرجات البحثية وتأثيرها.

1. Adler, R., Ewing, J., and Taylor, P. (2008) Citation statistics. A report from the International Mathematical Union.

2. Seglen, P.O. (1997) Why the impact factor of journals should not be used for evaluating research. BMJ 314, 498-502.

3. Editorial (2005). Not so deep impact. Nature 435, 1003-1004.

4. Vanclay, J.K. (2012) Impact Factor: Outdated artefact or stepping-stone to journal certification. Scientometric 92, 211-238.

5. The PLoS Medicine Editors (2006). The impact factor game. PLoS Med 3(6): e291 doi:10.1371/journal.pmed.0030291.

6. Rossner, M., Van Epps, H., Hill, E. (2007). Show me the data. J. Cell Biol. 179, 1091-1092.

7. Rossner M., Van Epps H., and Hill E. (2008). Irreproducible results: A response to Thomson Scientific. J. Cell Biol. 180, 254-255.

8. http://www.eigenfactor.org/

9. http://www.scimagojr.com/

10. http://opencitations.wordpress.com/2013/01/03/open-letter-to-publishers

11. http://altmetrics.org/tools/ 